\title{
Experimental Study on Variable-Amplitude Fatigue of Welded Cross Plate-Hollow Sphere Joints in Grid Structures
}

\author{
Jin-Feng Jiao $\mathbb{D},{ }^{1}$ Hong-Gang Lei $\mathbb{D},{ }^{1}$ and Y. Frank Chen $\mathbb{D}^{2,3}$ \\ ${ }^{1}$ School of Architecture and Civil Engineering, Taiyuan University of Technology, Taiyuan 030024, China \\ ${ }^{2}$ School of Engineering Technology, Southwest University, Chongqing 400716, China \\ ${ }^{3}$ Department of Civil Engineering, Penn State Harrisburg, 777 W. Harrisburg Pike, Middletown, PA 17057, USA \\ Correspondence should be addressed to Hong-Gang Lei; lhgang168@126.com and Y. Frank Chen; yxc2@psu.edu
}

Received 21 August 2017; Revised 15 November 2017; Accepted 27 December 2017; Published 21 March 2018

Academic Editor: Baozhong Sun

Copyright ( $\odot 2018$ Jin-Feng Jiao et al. This is an open access article distributed under the Creative Commons Attribution License, which permits unrestricted use, distribution, and reproduction in any medium, provided the original work is properly cited.

The fatigue stress amplitude of the welded cross plate-hollow sphere joint (WCPHSJ) in a grid structure varies due to the random loading produced by suspending cranes. A total of 14 specimens considering three different types of WCPHSJs were prepared and tested using a specially designed test rig. Four typical loading conditions, "low-high," "high-low," "low-high-low," and "high-lowhigh," were first considered in the tests to investigate the fatigue behavior under variable load amplitudes, followed by metallographic analyses. The experimental and metallographic analysis results provide a fundamental understanding on the fatigue fracture form and fatigue mechanism of WCPHSJs. Based on the available data from constant-amplitude fatigue tests, the variable-amplitude fatigue life of the three types of WCPHSJs was estimated using the Miner rule and Corten-Dolan theory. Since both accumulative damage theories yield virtually same damaging results, the Miner rule is hence suggested to estimate the fatigue life of WCPHSJs.

\section{Introduction}

The grid structure (Figure 1) is a highly indeterminate space structure. It has been widely used in industrial buildings, airplane hangar facilities, and public buildings due to the advantages of reasonable force distribution, simple construction, and large span $[1,2]$. Suspended cranes prevail in this type of structures, generating random repeated loadings to the joints of the grid structure, especially at the bottom chord (Figure 2). The fatigue failure at such joints could result in a structural collapse. The welded joint consisting of a hollow sphere (Figure 2) has been commonly used in practice, accounting for about $70 \%$ of total cases [3-5]. Therefore, the variable-amplitude fatigue behavior of welded hollow spherical joints (WHSJs) under random repeated loads warrants a further study.

Previous studies focused on the static behavior and ultimate bearing capacity of WHSJs under axial loading and/or in-plane bending. Han et al. [6] conducted experimental and numerical studies to investigate the ultimate bearing capacity of WHSJs with the sphere diameter of 160-900 mm under axial loads. Han and Liu [7] performed a full-scale joint test and nonlinear finite element analysis (FEA) to study the strength performance of a large spherical joint under multiaxial loads. Based on the experimental and FEA results, Dong et al. [8, 9] obtained the load-carrying capacity and proposed a practical calculation method for the WHSJs connecting square steel tubes under axial load, inplane bending moment, and the combination of them. Liu and Chen [10], Liu et al. [11], Hu et al. [12], and Wang and Wei [13] discussed the various bearing capacity formulas of WHSJs. Jiang et al. [14] studied the influence of different factors on the carrying capacity of WHSJs analytically and numerically. Xiong et al. [15] and Ji et al. [16] conducted the experimental study and FEA on full-scale large WHSJs under multiaxial loading. Liu et al. [17] studied the effect of WHSJ's rigidity on member forces analytically and validated it using the FE method.

The research on the constant-amplitude fatigue performance of the WHSJs in a grid structure is relatively limited, 


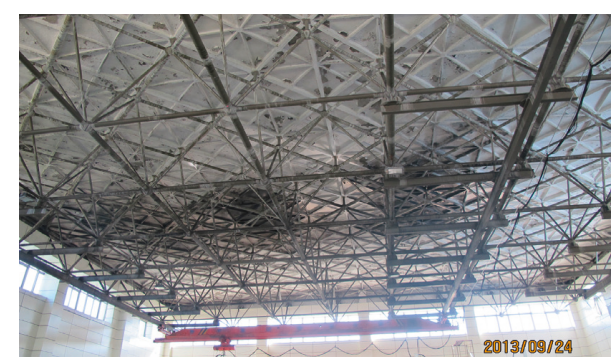

FIgURE 1: A coal cleaning plant in Shanxi, China.

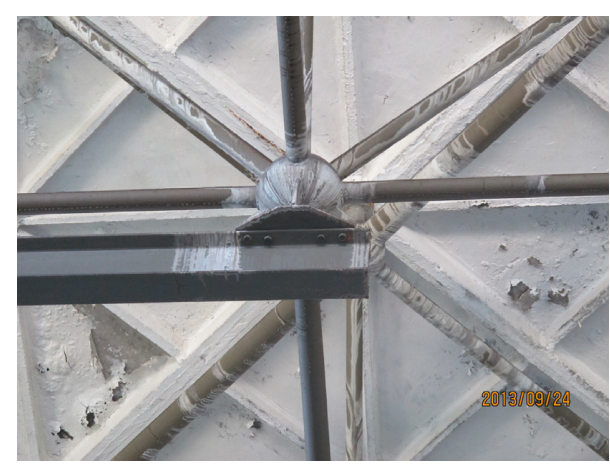

Figure 2: Welded hollow spherical joint.

mostly carried out in China. Lei $[3,4]$ conducted experiments and FEAs to investigate the stress distribution on the surface of WHSJs under multidirectional tension loads and proposed a useful formula for calculating the bearing capacity, the S-N fatigue curves, and a theoretical formula for determining the stress concentration factor (SCF) of a WPSJ. Xiao et al. [18, 19] utilized the test and FEA results to discuss the stress distribution and constant-amplitude fatigue performance of welded cross plate-hollow sphere joints (WCPHSJs) and concluded that the decisive factors for the joint stress were the width of plate and the thickness of sphere. Their study further states that, when the width of the cross plate is greater than a coefficient times the outside diameter of the tube, the fatigue resistance of the WCPHSJ is better compared to a welded tubehollow sphere joint. $\mathrm{Xu}$ and Cui [20] presented a method for calculating the fatigue life of a WHSJ, based on the field survey results of more than twenty factories with suspended cranes. They also stated that grid structures had much lower fatigue strength than a conventional steel structure and that the fatigue life of the suspended joint in a grid structure or the member directly connected with the joint should be calculated. Zhang et al. [21] discussed the key factors affecting the fatigue of large-scale welded structures through fatigue experiments. Jiao [22] collected and investigated 86 practical projects with suspended cranes and concluded that the fatigue issue should be considered for a grid structure with suspended cranes.

Appendix 3 of ANSI/AISC 360-16 [23] states that no evaluation of fatigue resistance of members consisting of structural shapes or plates is required if the number of cycles of repetitive loads is less than $2 \times 10^{4}$; for tension-loaded plate elements connected at their end by cruciform, $\mathrm{T}$, or corner details with welds (partial-joint-penetration groove, fillet, or the combination of them), when crack initiates from the toe of the weld on the tension-loaded plate element, the allowable stress range belongs to stress category C. However, this stress category is not suitable for WCPHSJs [24]. Part 1.9 in the current Eurocode3 [25] states that no provisions contained in Table 8.5 can be directly used for WCPHSJs and that fatigue tests should be carried out to determine the fatigue strength for details not included in the code. The current Chinese steel design code (GB50017-2003) [26] states that fatigue should be assessed for a steel member and its connections under repeated dynamic loading of $5 \times 10^{4}$ cycles or more. The current Chinese technical specification for space frame structures (JGJ7-2010) [27] also states that fatigue of a flat space with suspended cranes should be evaluated when the number of stress cycles exceeds $5 \times 10^{4}$. The relevant allowable stress value and construction should be determined by a special fatigue test. Code of practice for the structural use of steel [28] states that the basic S-N design curves for parent steels being dependent on the strength of the material should be developed based on the tests on small smooth laboratory specimens as a minimum requirement; if Miner's summation is unsatisfactory, modify the peak stress range or the joint classification so as to give a satisfactory value of under 1.0.

The fatigue accumulative damage theory is mainly used to estimate the fatigue life of a member or connection, in which the Miner rule is most common. The probabilitybased Miner rule was proposed to study the fatigue damage of concrete specimens and riveted joints $[29,30]$. Besides, a calculation formula for the equivalent fatigue stress amplitude under variable-amplitude loading was proposed by Zhu et al. [31], based on the Corten-Dolan theory.

Variable-amplitude fatigue study on WHSJs is even more limited. Consequently, current steel design specifications do not have a specific fatigue provision for WHSJs in a grid structure and only suggest that experimental verification should be performed. It is therefore essential to study further the fatigue of such joints in a gird structure. In this paper, both experimental and theoretical analyses on variable-amplitude fatigue behavior of WCPHSJs in a grid structure under random repeated loads are described and discussed along with a more reasonable estimation method for fatigue life.

\section{Experimental Program}

The repeated loads caused by the suspended cranes at the WCPHSJs in a grid structure are random and complex. As such, a load spectrum should be used in the fatigue test of suspended joints. However, acceptable standard fatigue load spectrum has not become available due to limited studies. In this study, a simplified fatigue load spectrum reflecting the random loads was adopted to perform the fatigue tests of WCPHSJs.

2.1. Specimen Design. The conducted tests include three types of details designed to represent the actual fatigue details of a grid structure with suspended cranes. They are labeled as KQ-4, KQ-5, and KQ-7, as shown in Figure 3. The fatigue design requires that the load capacity of a WCPHSJ be less than that of welded circular tube-hollow sphere to 


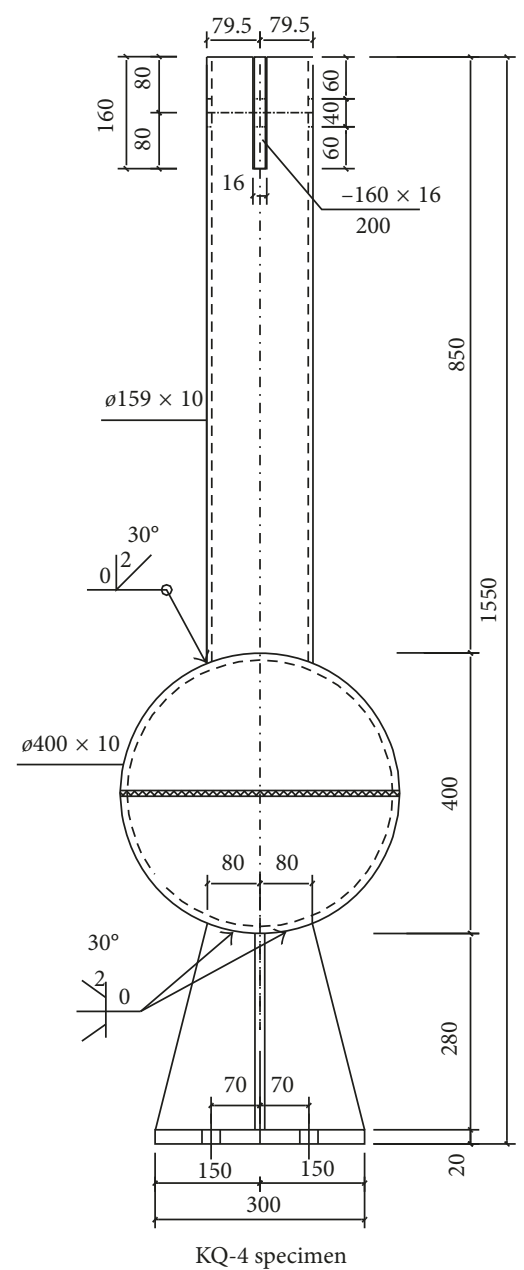

(a)

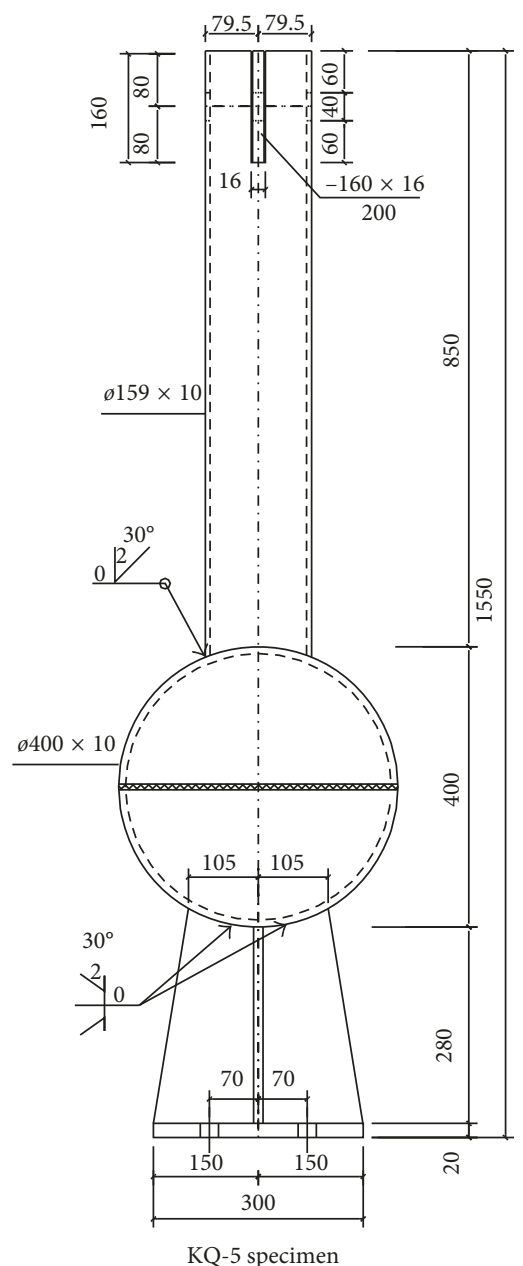

(b)

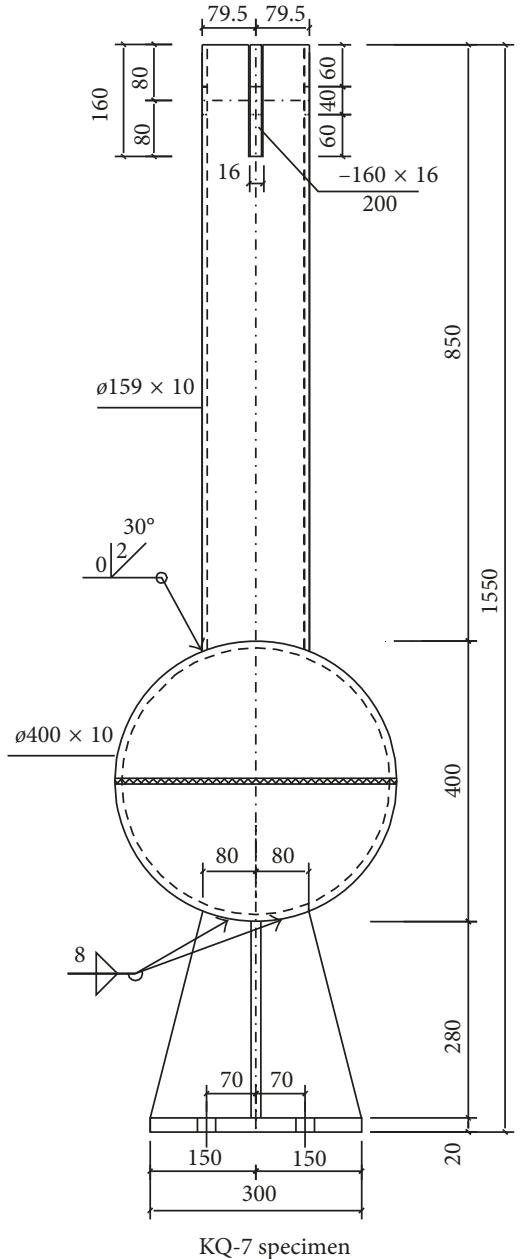

(c)

FIgURE 3: Fatigue details of the specimens. (a) KQ-4, (b) KQ-5, and (c) KQ-7.

TABLE 1: Geometrical characteristics of the specimens (unit: $\mathrm{mm}$ ).

\begin{tabular}{lccccc}
\hline Specimen label & Tested number & $D \times t$ & $d \times t_{1} / b \times t_{2}$ & $\alpha$ & Connection type \\
\hline KQ-4 & 5 & $\phi 400 \times 10$ & $\phi 159 \times 10 / 2-160 \times 10$ & 1.47 & Butt weld \\
KQ-5 & 7 & $\phi 400 \times 10$ & $\phi 159 \times 10 / 2-210 \times 10$ & 1.08 & Butt weld \\
KQ-7 & 2 & $\phi 400 \times 10$ & $\phi 159 \times 10 / 2-160 \times 10$ & 1.95 & Fillet weld \\
\hline
\end{tabular}

Note. $D$, diameter of welded hollow sphere; $t$, thickness of sphere; $d$, diameter of steel tube; $t_{1}$, thickness of steel tube; $b$, width of crossed plate; $t_{2}$, thickness of crossed plate; $\alpha$, limit strength ratio of steel tube welded sphere and cross plate welded sphere.

ensure the fatigue failure occurring at the WCPHSJ. The combination of butt and fillet welds was used for each joint type for specimens KQ-4 and KQ-5, while fillet welds with the root height $\left(h_{f}\right)$ of $8 \mathrm{~mm}$ were used for each joint type for specimens KQ-7 (Table 1).

The circular tube, welded hollow sphere, cross plate, and cover plate were fabricated from Q235B steel. The sphere meets the requirement of JG/T 11-2009 [32], and all welded hollow sphere joints were not stiffened.

2.2. Test Rig. The test rig (Figures 4 and 5) is intended to test the specimens to study the fatigue behavior of WCPHSJs under variable-amplitude loads. It was designed to be self-reacting and situated on the floor. Its setup was relatively easy. Preliminary fatigue tests have demonstrated that the test rig is efficient, stable, reliable, time saving, and cost effective.

2.2.1. Load Program. Based on the test rig, the variableamplitude fatigue tests of WCPHSJs were completed through a reasonably arranged loading sequence applicable to constant-amplitude fatigue tests. Four typical loading conditions including "low-high," "high-low," "high-lowhigh," and "low-high-low" were considered in the tests to investigate the fatigue behavior under variable load amplitudes. Two particular loading conditions were also considered, as described in the following. 


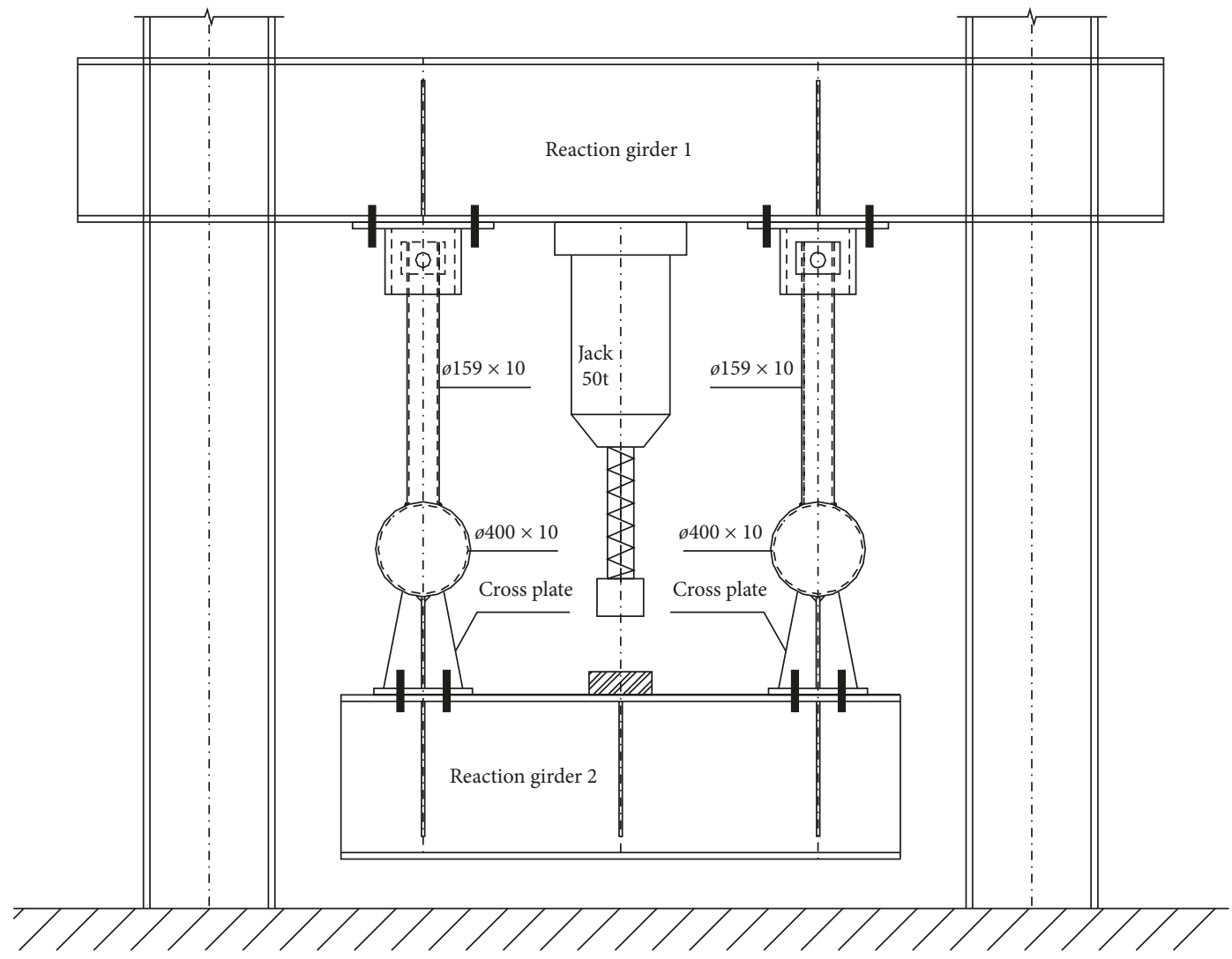

FIgUre 4: Central loading condition.

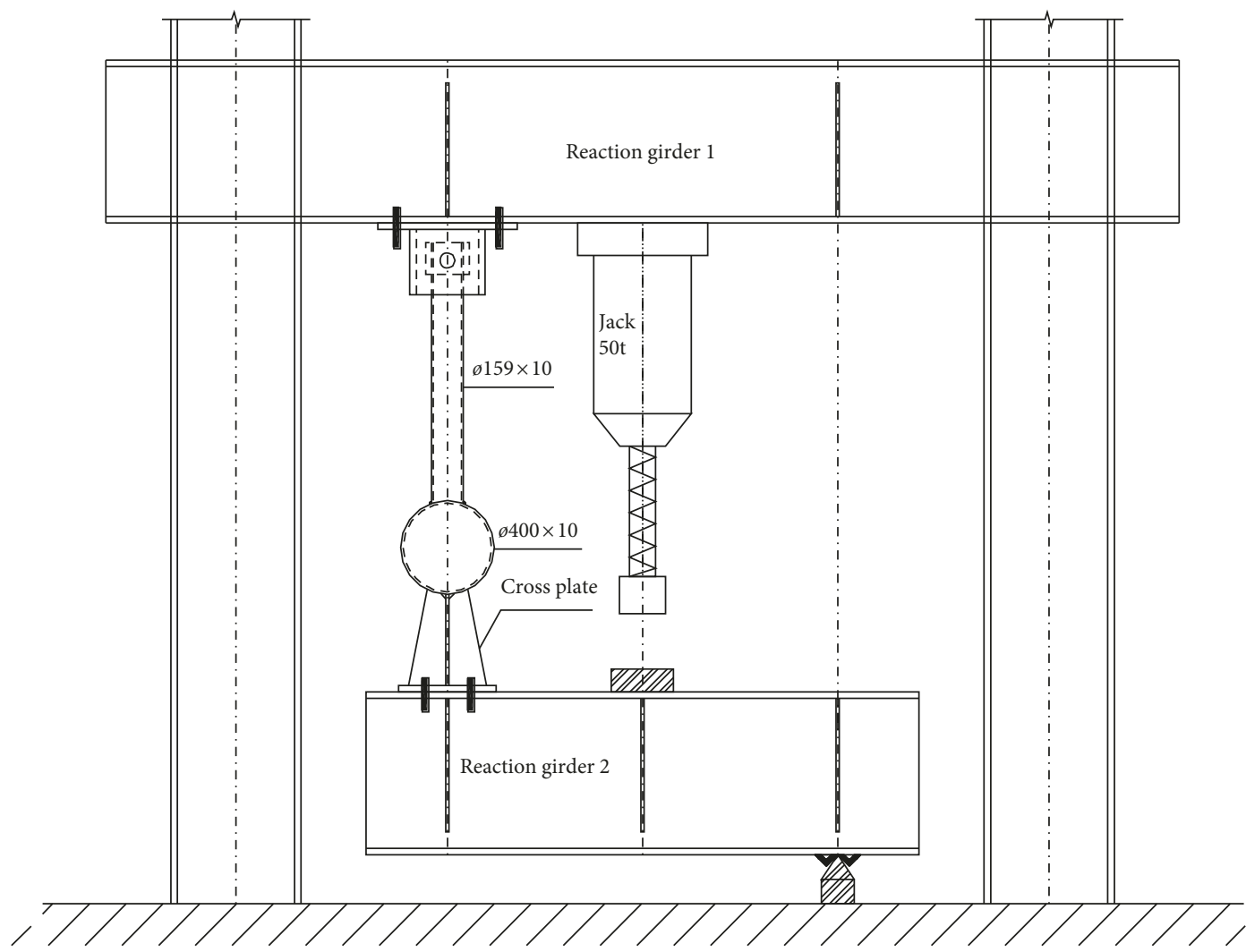

Figure 5: Unilateral loading condition. 
(1) Central Loading Condition (Figure 4). Two specimens were fixed on the steel beam in the test rig, with its bottom connected with a pair of M33 high-strength bolts and the top pinned with the rig by metal studs. The advantage of the central loading is that the loads can be simultaneously applied to two similar specimens. In addition, if one of the specimens fails in fatigue, then one of the following two alternatives may be considered: (1) replace the damaged specimen with a new one and then impose the load and (2) apply a further increased load to the undamaged specimen. The disadvantage of the central loading is that the maximum load is limited to 50 tons for each specimen as the fatigue machine can only accommodate 100 tons of load capacity totally.

(2) Unilateral Loading Condition (Figure 5). Based on the central loading condition, one of the two specimens was removed and the pinned support was set at the corresponding location under the bottom flange of the beam. The load applied by the actuator was transferred to the specimen on the other side of the beam in order to simulate the unilateral loading condition. The actuator should be kept close to the specimen to eliminate the shaking of the rig.

2.2.2. Test Equipment. The Swiss made AMSLER fatigue test machine was used to simulate the constant- and variableamplitude fatigue loads on specimens during the test. The heaviest load applied to the specimen was generated by the $1000 \mathrm{kN}$ hydraulic pressure servo fatigue machine at the frequency of $6.67 \mathrm{~Hz}$. The loading cycle followed a controlled smooth sine wave.

2.3. Fatigue Test Results and Fatigue Failure Modes. The variable-amplitude fatigue test was performed on WCPHSJ specimens. A reasonable definition of fatigue failure is necessary in order to analyze the fatigue test results. In this study, the observed through sphere wall fatigue crack is taken as the failure criterion to record the fatigue cycle number for the specimen [33]. During the entire experimental process, observations were made at an interval of 1-2 hours to detect if any fatigue crack occurs on the specimen and to determine if the test should be stopped.

2.3.1. Test Results. Based on the test rig and predetermined load program, 3 types for a total of 14 specimens were tested under different variable-amplitude loads. The test results are summarized in Table 2.

2.3.2. Fatigue Failure Modes. According to the analysis of broken specimens, all 3 different specimen types appear to display a similar fatigue failure mode; namely, the fatigue crack initiated on the edge of the weld toe at the joint between the cross plate and the sphere and then propagating circumferentially around the sphere to a diameter equal to the cross plate width. The typical failure mode of the specimens is shown in Figure 6.
2.3.3. Metallographic Analysis of Fatigue Fracture. Metallographic analysis is an important tool for detecting the fracture form of a material or member and provides the relevant fatigue fracture details. It can also provide the important information of crack initiation, crack propagation, and final fracture. Scanning electron microscope (TESCAN Mira3 LMH) was used to observe the precise fatigue fracture form and features. Through the constantamplitude fatigue tests on specimens KQ-4 and KQ-5, macroscopic and microscopic metallographic analyses were made to determine the fatigue fracture mechanism of WCPHSJs.

Typical fatigue fracture surfaces for specimens KQ-4-5/7 and KQ-5-4 are described as follows. Figures 7 and 8 show that the initial defects induced from manufacturing, pores, and inclusions are the main source contributing to the fatigue problem.

The two initial crack sources in KQ-4-5 fatigue fracture surfaces were magnified by about 40 times (Figures 9 and 10) to observe more closely the characteristics of the fatigue source. The two fatigue propagation regions magnified 500 times (Figures 11 and 12) show that the depth and spacing of shell-like lines situated on both sides of fatigue formation are obviously different; the first fatigue formation grows in the fatigue source region, while the second lies in the fatigue crack propagation region. In addition, both fatigue phases are perpendicular to the shell-like lines and extend radially; the fatigue crack source in KQ-4-5 (I) precedes that in KQ-4-5 (II).

Figure 13 shows that the sinking region lies in the middle of the fatigue fracture, which has the traces of extrusion and friction and radial shell-like lines around. The initial crack sources in KQ-4-7 fatigue fracture surfaces were magnified by 60 times as shown in Figure 14 which clearly indicates that some small black voids exist in the fatigue sources and that the developed fatigue zone is flat and smooth with radial shell-like lines. The fatigue propagation region magnified by 2000 times (Figure 15) shows the clear macro-shell-like lines and patterns.

The initial crack sources in KQ-5-4 fatigue fracture surfaces were magnified by 20 times (Figures 16 and 17) to better observe that the fatigue source zone is flat and smooth with radial shell-like lines, displaying several fatigue stages. The final fatigue rupture region was magnified by 200 times as shown in Figure 18, clearly indicating the disorder morphology with dimples. The tear stripes were obviously displaying the static load tensile failure fracture morphology. The fatigue propagation region magnified by 500 times (Figure 19) shows parallel fatigue patterns and a number of secondary cracks.

Table 2 shows that the fatigue life of WCPHSJs is influenced somewhat by the welding connection type, plate width, and loading sequence. The conclusions are as follows: (1) the specimen with butt welding (KQ-7) has longer fatigue life than that with fillet welding (KQ-4); (2) the fatigue life of specimens KQ-4 and KQ-5 is generally proportional to the plate width; and (3) for the same specimen (e.g., KQ-4), the fatigue life under "high-low" loading is 1.6-3.6 times of that under "low-high" loading. 
TABLE 2: The variable-amplitude fatigue test data of WCPHSJ under program block.

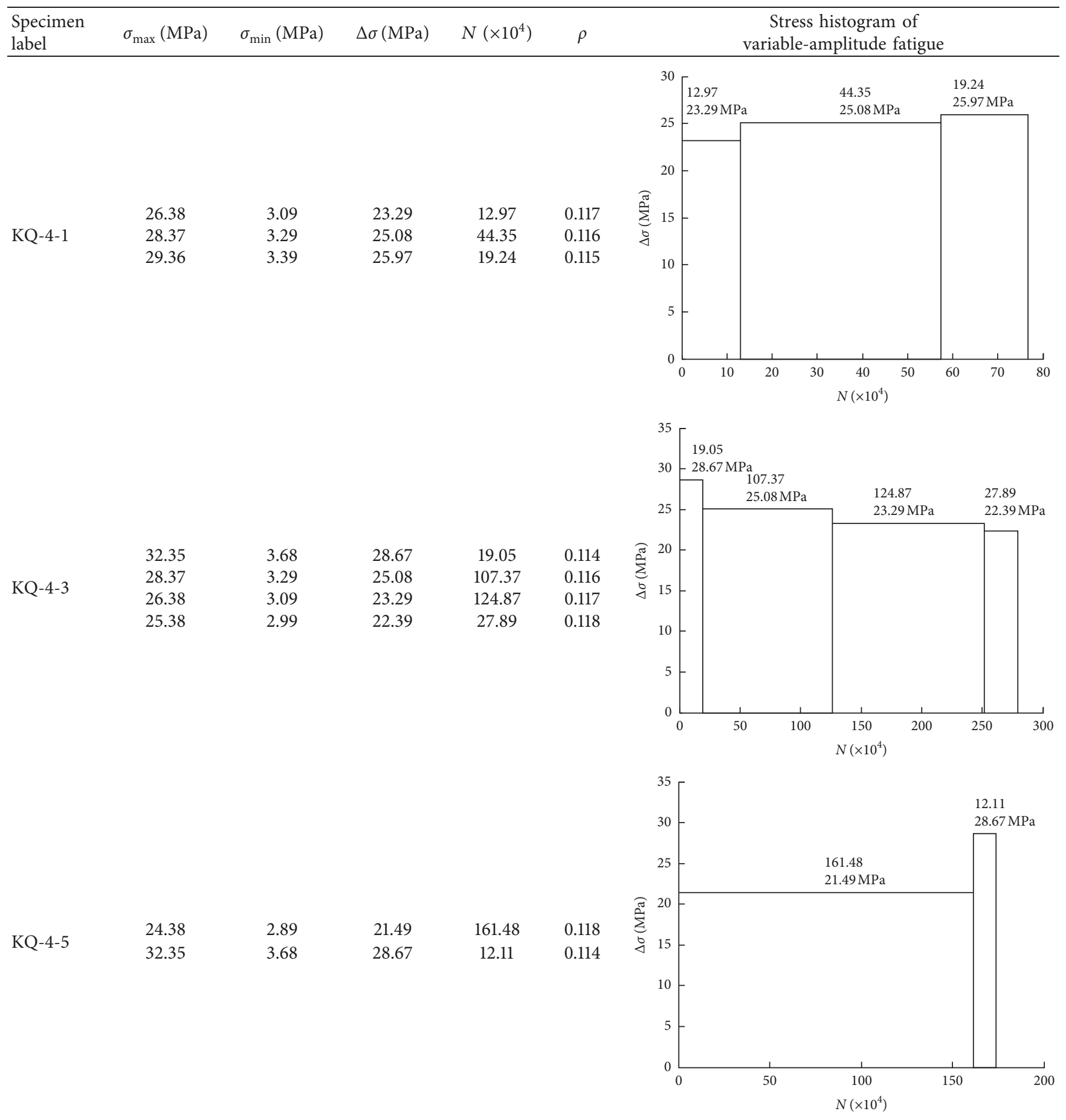


Table 2: Continued.

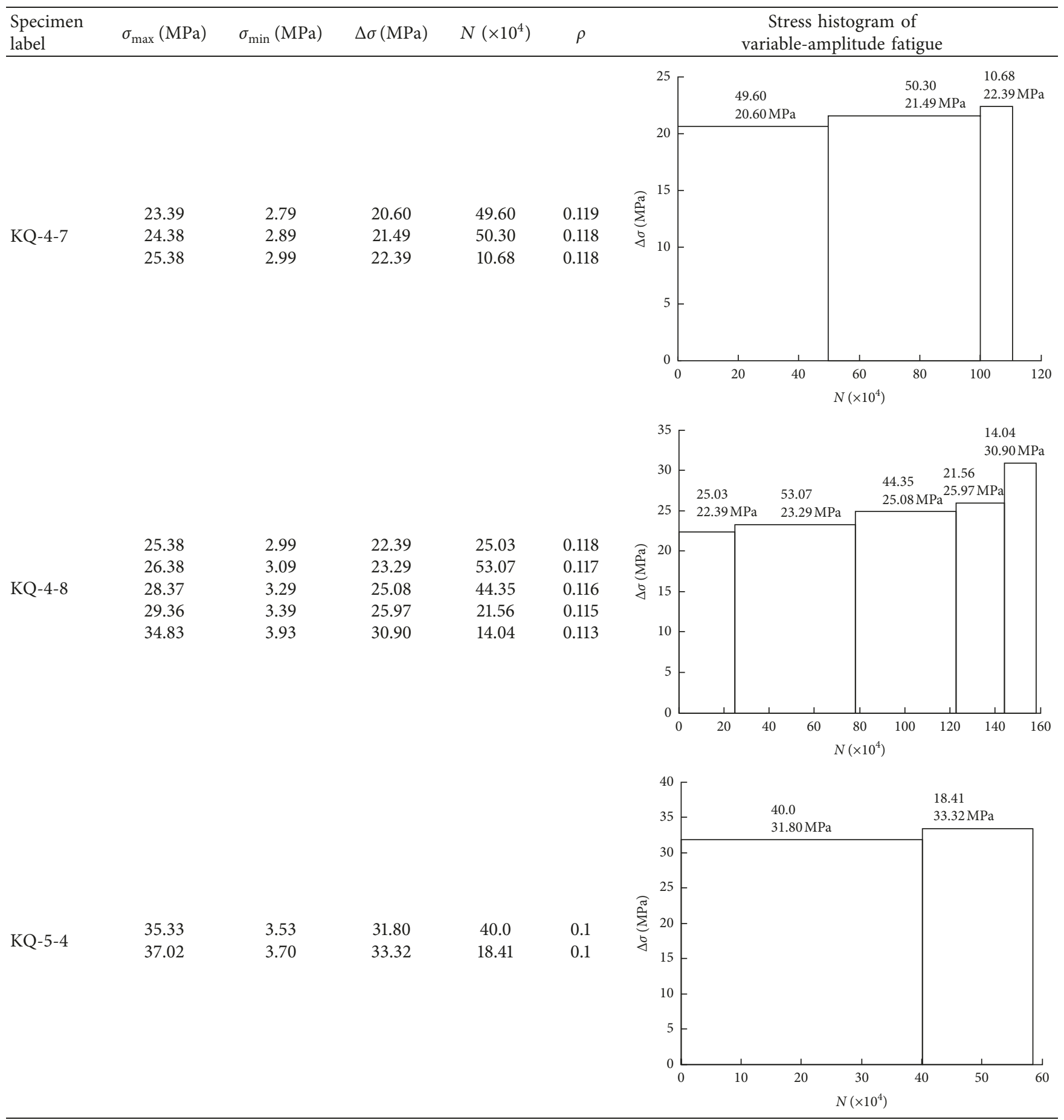


Table 2: Continued.

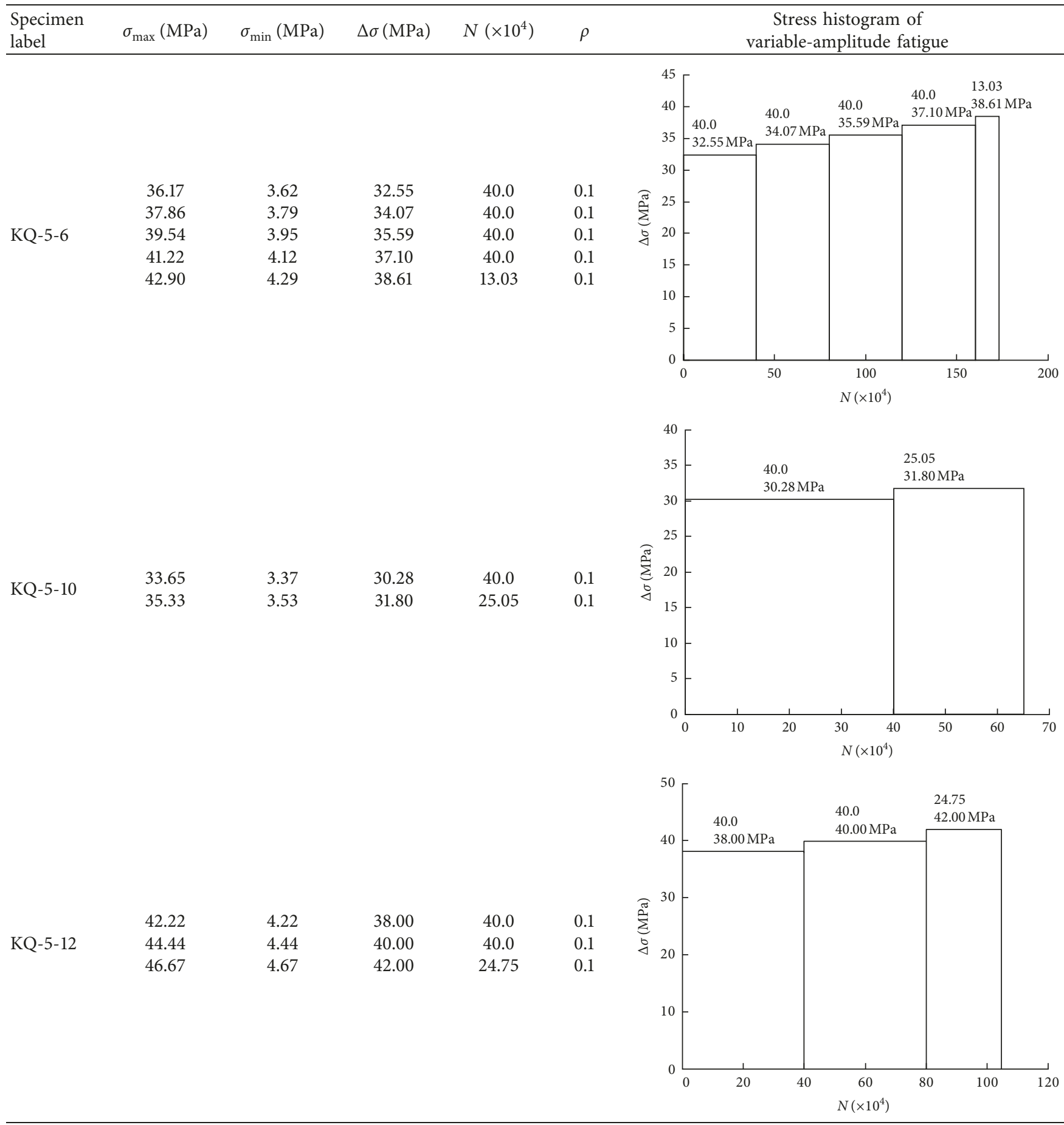


TABle 2: Continued.

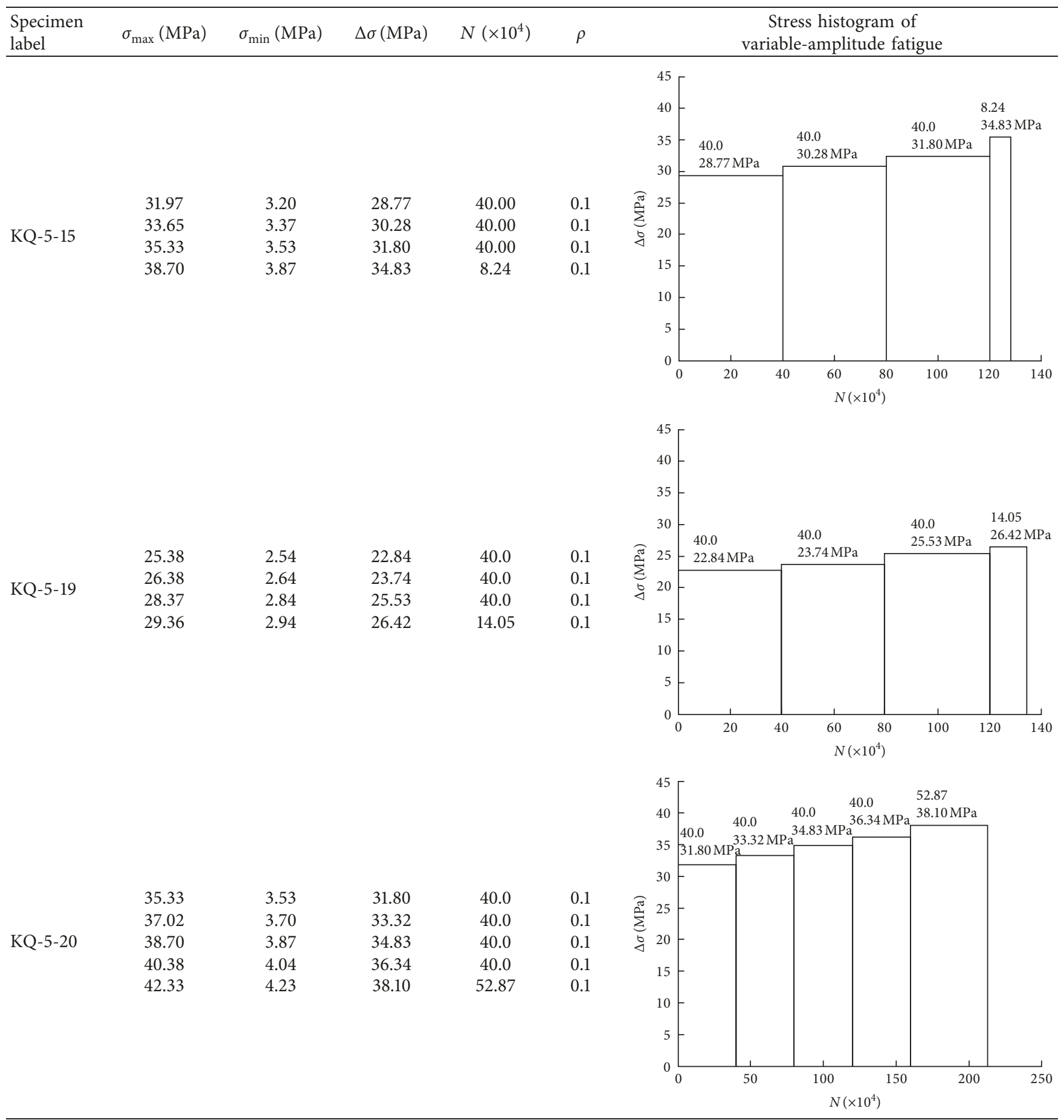


TABle 2: Continued.

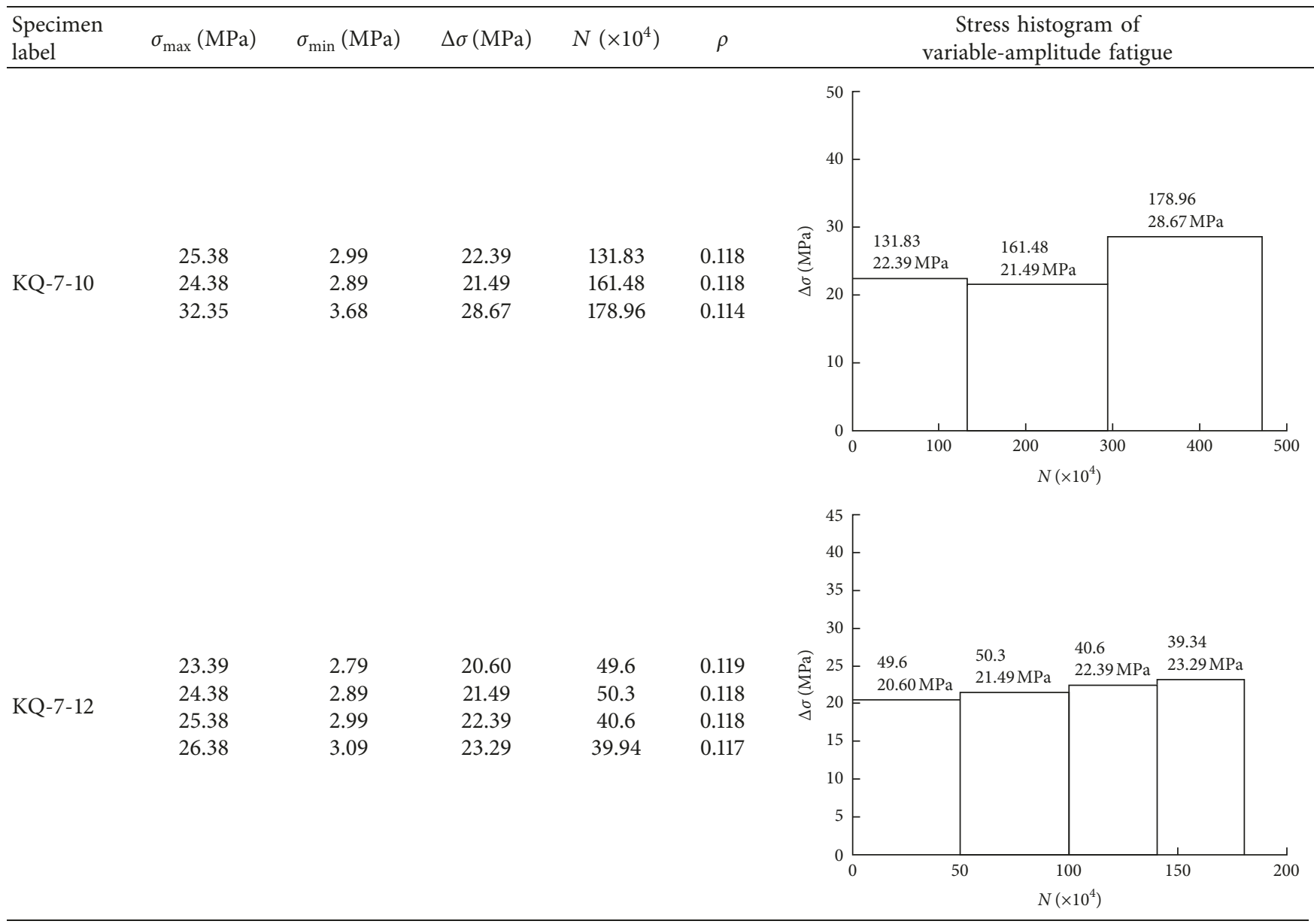

Note. $F$, axial load of fatigue specimens $(\mathrm{kN}) ; b$, width of crossed plate; $t$, thickness of sphere; $\sigma=F / \pi b t$, nominal stress of fatigue specimens; $\Delta \sigma=\sigma_{\max }-\sigma_{\min }$, stress range; $\rho=\sigma_{\min } / \sigma_{\max }$, stress ratio.

\section{Analysis of the Variable-Fatigue Test Results}

3.1. The Constant-Amplitude Fatigue Test Results of WCPHSJs. A total of 19 valid constant-amplitude fatigue test data covering 5 types (KQ-4, KQ-5, KQ-6, KQ-7, and KQ-8, as shown in Table 3) of WCPHSJs were statistically analyzed, followed by the derivations of the S-N curve (Figure 20) and (1) [22]. Note that the preparation of specimens is the same between constant-amplitude and variable-amplitude tests, but with different dimensions of joint components. The constant-amplitude fatigue test results are summarized in Table 4 . The fatigue tests show that the stress ratio has little influence on the fatigue life of WCPHSJs, and so the stress ratio is not considered.

$$
\begin{aligned}
\lg (N) & =10.9800-3.5073 \lg (\Delta \sigma) \pm 0.2456 \\
r & =-0.7633 \\
{[\Delta \sigma]_{2 \times 10^{6}} } & =18.38 \mathrm{MPa},
\end{aligned}
$$

where $r$ is the correlation coefficient and $[\Delta \sigma]_{2 \times 10^{6}}$ is the allowable maximum nominal stress range corresponding to $2 \times 10^{6}$ loading cycles.
3.2. Analysis of the Variable-Amplitude Fatigue Test Data. Referring to Table 2, a total of 14 specimens were tested using the AMSLER fatigue test machine. Miner's rule and the Corten-Dolan theory ((2)-(4)), representative of the linear cumulative damage theory, were used to assess the variableamplitude test data and the results are summarized in Table 5.

(1) Miner's Rule $[28,34]$. The total fatigue damage $(D)$ is calculated by

$$
D=\sum_{1}^{i} \frac{n_{i}}{N_{i}} \leq 1,
$$

where $n_{i}$ is the number of applied load cycles of type $i$ and $i$ is the pertinent fatigue life.

Miner's rule states that fatigue failure occurs when $D=1.0$.

(2) Corten-Dolan Theory [31, 34, 35]. The Corten-Dolan theory is a revised linear cumulative damage theory, in which the total number of cycles to failure $\left(N_{g}\right)$ is determined by

$$
N_{g}=\frac{N_{1}}{\sum \alpha_{i}\left(\sigma_{i} / \sigma_{1}\right)^{d}},
$$




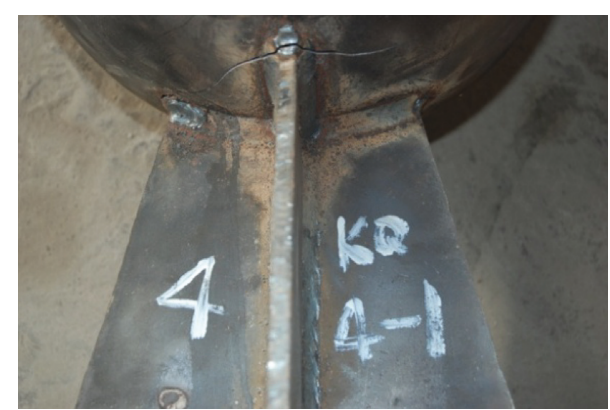

Figure 6: Failure mode of specimen KQ-4-1.

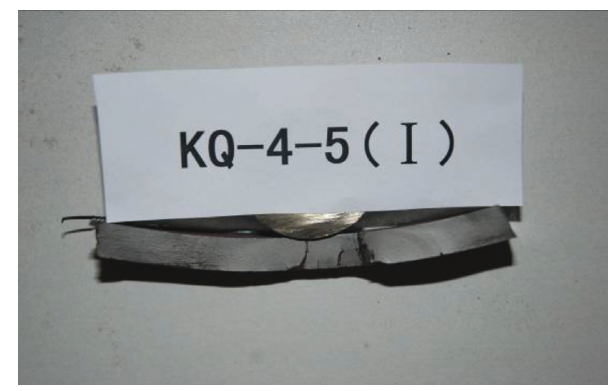

FIgURe 7: Macrofracture surface of KQ-4-5(I).

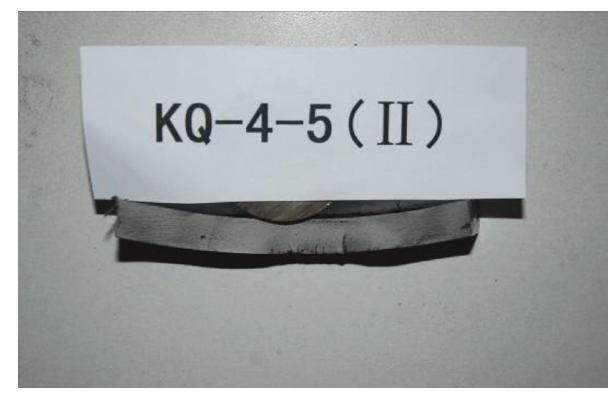

FIgURE 8: Macrofracture surface of KQ-4-5(II).

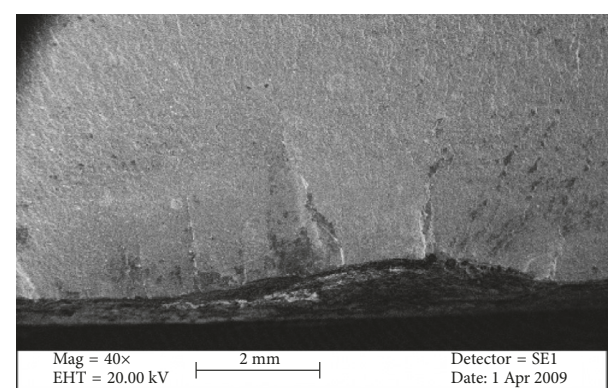

Figure 9: Microfracture surface of KQ-4-5(I) magnified by 40 times.

where $N_{1}$ is the number of cycles to failure at $\sigma_{1}, d$ is the Corten-Dolan exponent, $\sigma_{1}$ is the maximum stress, $\sigma_{i}$ is the $i$ th level stress amplitude $(i=1,2, \ldots, k), n_{i}$ is the number of cycles corresponding to $\sigma_{i}$, and $\alpha_{i}$ is the proportion of the stresses at $\sigma_{i}\left(=n_{i} / N_{g}\right)$.

The exponent $d$, as a material constant, was derived from the two-step cycle loading test $[31,35]$. In this study, only 3

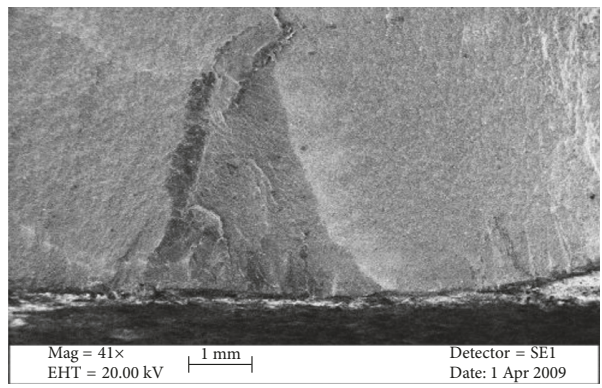

Figure 10: Microfracture surface of KQ-4-5(II) magnified by 41 times.

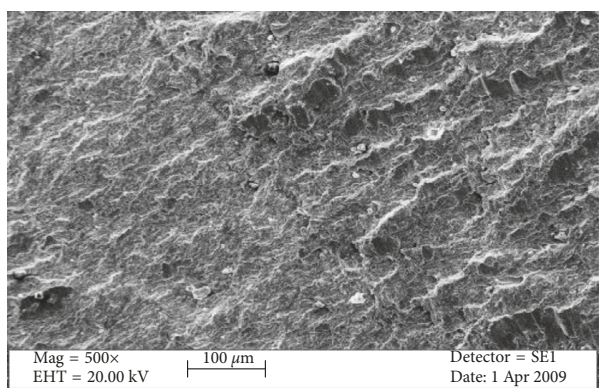

Figure 11: Microfracture surface of KQ-4-5(I) magnified by 500 times.

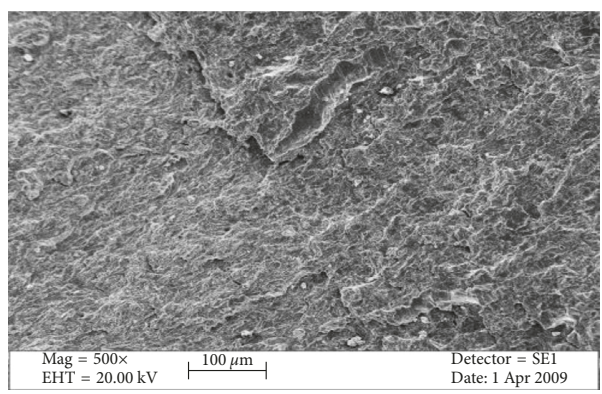

Figure 12: Microfracture surface of KQ-4-5(II) magnified by 500 times.

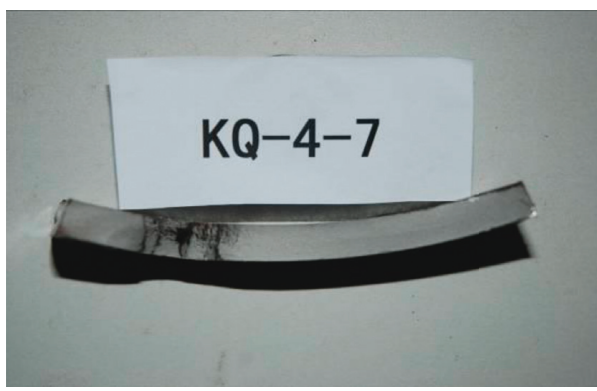

FIgURE 13: Macrofracture surface of KQ-4-7.

fatigue specimens (KQ-4-5, KQ-5-4, and KQ-5-10) were tested under the two-step loading, and other specimens were tested under the multistep loading. The calculated $d$ values for the three specimens are 3.39, 18.69, and 27.09 which are 


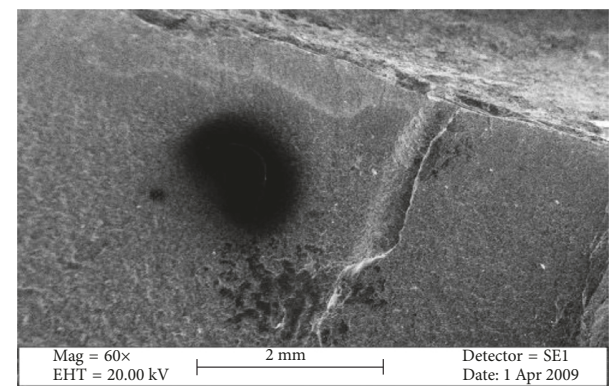

Figure 14: Microfracture surface of KQ-4-7 magnified by 60 times.

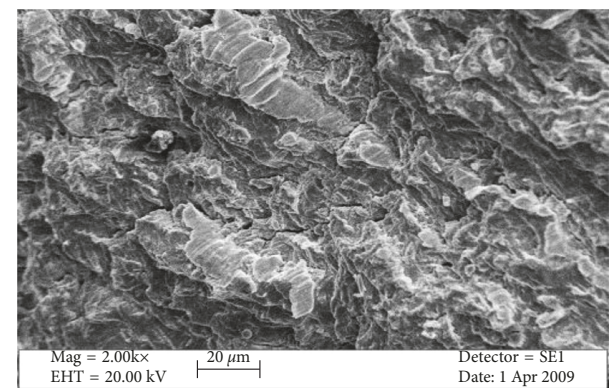

Figure 15: Microfracture surface of KQ-4-7 magnified by 2000 times.

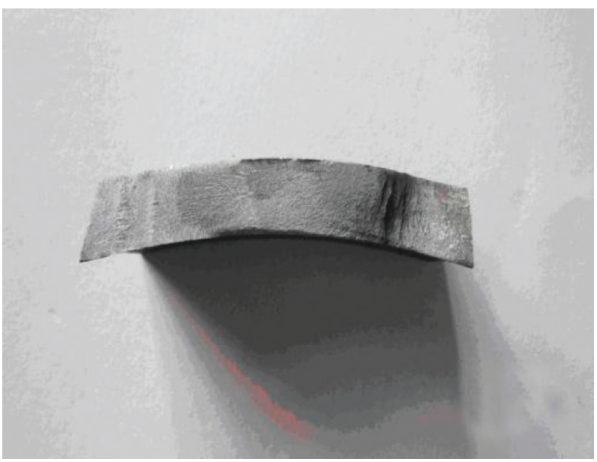

FiguRE 16: Macrofracture surface of KQ-5-4.

apparently dispersed. Based on the published $d=4.8$ [34] and the principle of proximity, the exponent $d=3.39$ was chosen in the variable-amplitude fatigue test. Substituting $d=3.39$ into (3), the following equation for $D$ (total fatigue damage) can be obtained:

$$
D=\frac{\alpha_{i} N_{g}}{\sum N_{1}\left(\sigma_{1} / \sigma_{i}\right)^{d}} \leq 1
$$

Table 5 shows that both $D$ values deduced from the above two accumulative damage theories differ only 3\% at the worst. Considering its simplicity, the Miner rule may be used to estimate the fatigue life of WCPHSJs.

3.3. Analysis of the Estimation of Fatigue Life. Table 5 indicates that the calculated values from the current linear cumulative damage theory do not always match with the

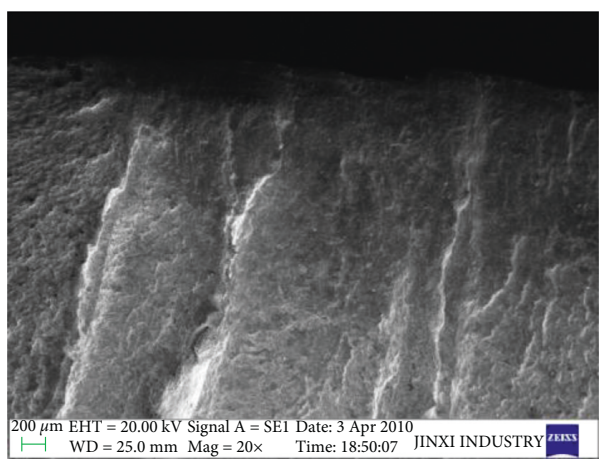

FIGURE 17: Microfracture surface of KQ-5-4 magnified by 20 times.

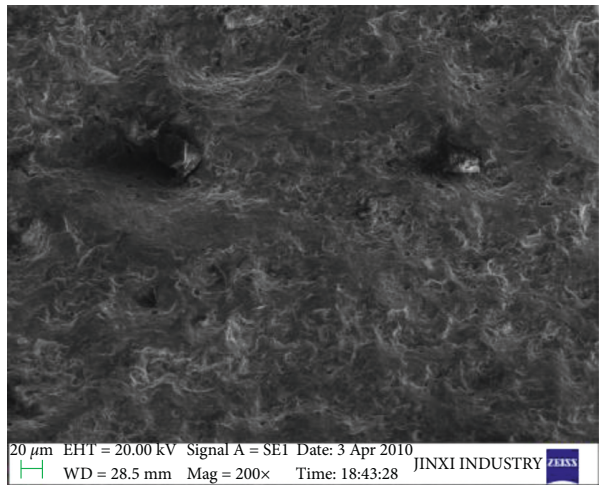

FIgURE 18: Microfracture surface of KQ-5-4 magnified by 200 times.

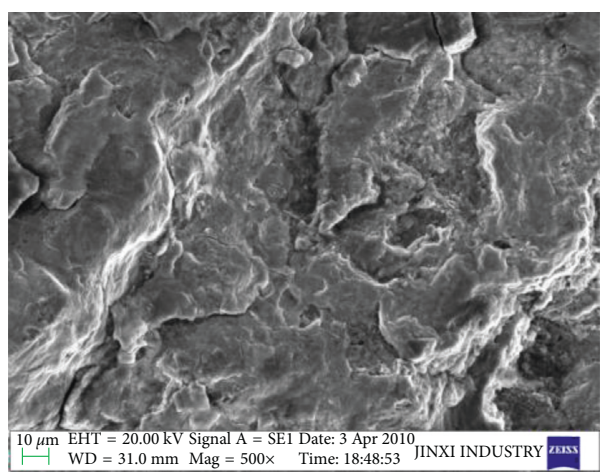

FIgURE 19: Microfracture surface of KQ-5-4 magnified by 500 times.

experimental data. This is because of the assumptions made in the cumulative damage theory which does not reflect the actual condition. Miner's rule assumes that (1) the effect of loading sequence and interval time on fatigue life is ignored and (2) the interaction between different loading levels is also neglected. Note that the Corten-Dolan theory is mainly used in the two-step fatigue loading.

During the variable-amplitude fatigue test, under the four different multistress random loading modes, the $D$ (total fatigue damage) values of all specimens appear to be scattered. $64.3 \%$ of the $D$ values are greater than 1.0 , implying a fatigue failure. The main reasons for this are (1) that all fatigue spectra are in tension-tension cycle and the 
TABLE 3: Geometrical characteristics of the constant-amplitude fatigue specimens (unit: $\mathrm{mm}$ ).

\begin{tabular}{lccccc}
\hline Specimen label & Tested number & $D \times t$ & $d \times t_{1} / b \times t_{2}$ & $\alpha$ & Connection type \\
\hline KQ-4 & 3 & $\phi 400 \times 10$ & $\phi 159 \times 10 / 2-160 \times 10$ & 1.47 & Butt weld \\
KQ-5 & 6 & $\phi 400 \times 10$ & $\phi 159 \times 10 / 2-210 \times 10$ & 1.08 & Butt weld \\
KQ-6 & 2 & $\phi 400 \times 10$ & $\phi 159 \times 10 / 2-260 \times 10$ & 1.03 & Butt weld \\
KQ-7 & 7 & $\phi 400 \times 10$ & $\phi 159 \times 10 / 2-160 \times 10$ & 1.95 & Fillet weld \\
KQ-8 & 1 & $\phi 400 \times 10$ & $\phi 159 \times 10 / 2-210 \times 10$ & 1.40 & Fillet weld \\
\hline
\end{tabular}

Note. $D$, diameter of welded hollow sphere; $t$, thickness of sphere; $d$, diameter of steel tube; $t_{1}$, thickness of steel tube; $b$, width of crossed plate; $t_{2}$, thickness of crossed plate; $\alpha$, limit strength ratio of steel tube welded sphere and cross plate welded sphere.

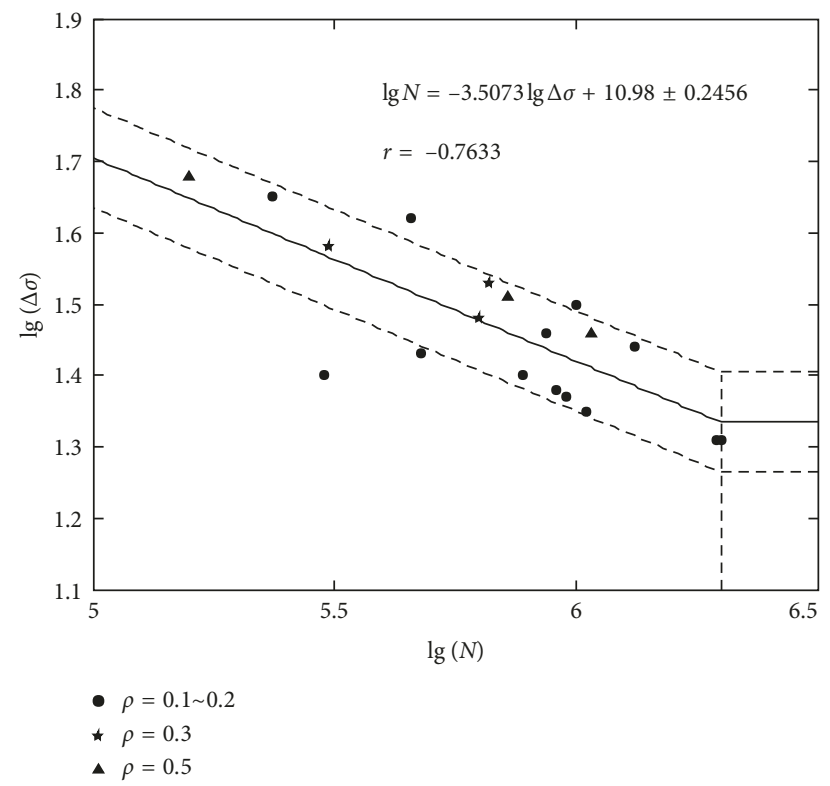

Figure 20: Constant amplitude S-N data: $\lg (\Delta \sigma)-\lg N$ curves.

TABLE 4: The test results of welded cross plate-hollow sphere joints under constant amplitude load.

\begin{tabular}{lcccccc}
\hline Specimen label & $\sigma_{\max }(\mathrm{MPa})$ & $\sigma_{\min }(\mathrm{MPa})$ & $\Delta \sigma(\mathrm{MPa})$ & $\lg (\Delta \sigma)$ & $N\left(\times 10^{4}\right)$ & $\lg (N)$ \\
\hline KQ-4-2 & 35.31 & 3.97 & 31.34 & 1.50 & 100.47 & 6.00 \\
KQ-4-4 & 25.38 & 2.99 & 22.39 & 1.35 & 104.03 & 6.02 \\
KQ-4-6 & 23.39 & 2.79 & 20.60 & 1.31 & 200 & 6.30 \\
KQ-5-1 & 26.92 & 3.03 & 23.89 & 1.38 & 90.27 & 5.96 \\
KQ-5-2 & 48.96 & 14.69 & 34.27 & 1.53 & 65.41 & 5.82 \\
KQ-5-3 & 43.52 & 13.05 & 30.47 & 1.48 & 62.71 & 0.119 \\
KQ-5-8 & 46.54 & 4.65 & 41.88 & 1.62 & 46.11 & 0.300 \\
KQ-5-13 & 95.6 & 47.8 & 47.8 & 1.68 & 15.72 & 5.66 \\
KQ-5-18 & 49.08 & 4.91 & 44.17 & 1.65 & 23.70 & 5.20 \\
KQ-6-14 & 57.7 & 28.8 & 28.8 & 1.46 & 106.37 & 5.37 \\
KQ-6-17 & 65.3 & 32.7 & 32.7 & 1.51 & 72.8 & 0.103 \\
KQ-7-1 & 32.35 & 3.68 & 28.66 & 1.46 & 87.27 & 5.86 \\
KQ-7-2 & 23.39 & 2.79 & 20.60 & 1.31 & 196.44 & 5.90 \\
KQ-7-4 & 31.35 & 3.58 & 27.77 & 1.44 & 131.60 & 6.100 \\
KQ-7-6 & 30.36 & 3.49 & 26.87 & 1.43 & 47.59 & 0.500 \\
KQ-7-11 & 28.37 & 3.29 & 25.08 & 1.40 & 30.10 & 0.500 \\
KQ-7-13 & 28.37 & 3.29 & 25.08 & 1.40 & 77.27 & 0.114 \\
KQ-7-14 & 26.38 & 3.09 & 23.29 & 1.37 & 94.54 & 0.119 \\
KQ-8-1 & 54.40 & 16.33 & 38.08 & 1.58 & 30.94 & 0.114 \\
\hline
\end{tabular}

Note. $F$, axial load of fatigue specimens $(\mathrm{kN}) ; b$, width of crossed plate; $t$, thickness of sphere; $\sigma=F / \pi b t$, nominal stress of fatigue specimens; $\Delta \sigma=\sigma_{\max }-\sigma_{\min }$, stress range; $\rho=\sigma_{\min } / \sigma_{\max }$, stress ratio. 
TABLE 5: The calculated result form based on the two theories.

\begin{tabular}{|c|c|c|}
\hline \multirow{2}{*}{ Specimen label } & \multicolumn{2}{|c|}{ Total fatigue damage, $D$} \\
\hline & Miner's rule & Corten-Dolan theory \\
\hline KQ-4-1 & 0.65 & 0.65 \\
\hline KQ-4-3 & 2.15 & 2.19 \\
\hline KQ-4-5 & 0.96 & 0.99 \\
\hline KQ-4-7 & 0.52 & 0.52 \\
\hline KQ-4-8 & 1.32 & 1.35 \\
\hline KQ-5-4 & 1.20 & 1.21 \\
\hline KQ-5-6 & 4.83 & 4.88 \\
\hline KQ-5-10 & 1.14 & 1.15 \\
\hline KQ-5-12 & 4.48 & 4.50 \\
\hline KQ-5-15 & 2.20 & 2.24 \\
\hline KQ-5-19 & 0.92 & 0.92 \\
\hline KQ-5-20 & 5.95 & 6.00 \\
\hline KQ-7-10 & 3.98 & 4.03 \\
\hline KQ-7-12 & 0.95 & 0.96 \\
\hline
\end{tabular}

mean stress of each cycle is greater than zero; (2) that the low-loading condition can produce the effect of "excitation," such as KQ-5-4; (3) different stress loading conditions, causing nonuniform damage to the member or joint under the same stress level; (4) the inevitable breakdown of the test machine, forcing the replacement of the specimen and thus interrupting the test.

\section{Key Findings}

Based on the variable-amplitude fatigue tests, metallographic analyses, and linear cumulative damage theory, the following key findings are offered:

(1) The metallographic analysis shows that the unavoidable initial welding defects caused by the surface processing may lead to a fatigue failure at the joint. Fatigue failure generally occurs at the weld toe location where severe stress is concentrated. For welded cross plate-hollow sphere joints, fatigue cracks generally initiate at the weld toe and then propagate circumferentially around the sphere to a diameter equivalent to the width of the cross plate until fatigue fracture.

(2) The analyses of the variable-amplitude fatigue tests indicate that the $D$ values obtained from the two accumulative damage theories are virtually the same. Miner's rule is suggested to estimate the fatigue life of WCPHSJs due to its simplicity.

(3) The four adopted loading conditions can efficiently simulate the variable-amplitude fatigue tests, but the difference between the actual and test loading conditions appears to be distinct. Hence, it is suggested that a more representative fatigue loading spectrum be developed in the future.

\section{Conflicts of Interest}

The authors declare that they have no conflicts of interest.

\section{Acknowledgments}

The authors are grateful to the financial supports provided by the Natural Science Foundation of China (NSFC) through Grant no. 51578357, the Natural Science Foundation of Shanxi Province of China through Grant no. 2015011062, and Talent Training Program in the postgraduate joint training base of Shanxi Province of China through Grant no. 2016JD11.

\section{References}

[1] H.-G. Lei and D.-Y. Yin, "Research progress on fatigue of grid structure with suspension cranes," Spatial Structures, vol. 14, no. 4, pp. 32-36, 2008, in Chinese.

[2] L. Su, S.-L. Zhu, N. Xiao, and B.-Q. Gao, "An automatic grid generation approach over free-form surface for architectural design," Journal of Central South University, vol. 21, no. 6, pp. 2444-2453, 2014.

[3] H.-G. Lei, "Research on static and fatigue behavior of welded hollow spherical joints in space trussed," Journal of Building Structures, vol. 14, no. 1, pp. 2-7, 1993, in Chinese.

[4] H.-G. Lei, "A analysis on the surface stress of welded hollow sphere joint," Journal of Taiyuan University of Technology, vol. 25, no. 1, pp. 10-17, 1994, in Chinese.

[5] Y.-C. Tan, T.-E. Lan, Y.-D. Yang, and R.-J. Qian, Experimental Investigation of the Load-Bearing Behavior of Hollow Spherical Joint for Space Truss and Its Rational Design: Selected Papers of Space Structure, Chinese Science Publishing and Media Ltd., Beijing, China, 1985, in Chinese.

[6] Q.-H. Han, Y.-D. Pan, and X.-L. Liu, "Analysis for the ultimate tensile and compressive bearing capacity of welded hollow spherical joints," China Civil Engineering Journal, vol. 36, no. 10, pp. 1-6, 2003, in Chinese.

[7] Q.-H. Han and X.-L. Liu, "Ultimate bearing capacity of the welded hollow spherical joints in spatial reticulated structures," Engineering structures, vol. 26, no. 1, pp. 73-82, 2004.

[8] S.-L. Dong, L. Xing, Y. Zhao, L. Gu, and X.-Y. Fu, "Loadcarrying capacity and practical calculation method of welded hollow spherical joints connected with square steel tubes," Journal of Building Structures, vol. 26, no. 6, pp. 27-37, 2005, in Chinese.

[9] S.-L. Dong, L. Xing, Y. Zhao, L. Gu, and X.-Y. Fu, "Simplified theoretical solution and practical calculation method for welded hollow spherical joints of rectangular hollow section members," China Civil Engineering Journal, vol. 39, no. 6, pp. 12-18, 2006, in Chinese.

[10] X.-L. Liu and Z.-H. Chen, "Analysis of collapse mechanism of welded hollow sphere joint in space trusses and experimental research of its bearing capacity," Journal of Building Structures, vol. 15, no. 3, pp. 38-44, 1994, in Chinese.

[11] X.-L. Liu, X.-J. Zhou, Y. Ding, and L.-Z. Xu, "Analysis of failure mechanism of super large diameter welded hollow spherical joint in space trussed and experimental study of its bearing capacity," Journal of Building Structures, vol. 19, no. 6, pp. 33-39, 1998, in Chinese.

[12] W.-S. Hu, P. Huang, and H.-B. Hu, "Study on the bearing capacity formula of welded hollow spheres in space trusses," Building Science, vol. 3, pp. 39-42, 1995, in Chinese.

[13] X.-L. Wang and L. Wei, "Ultimate bearing capacity of largescale welded hollow spherical joint in tests," Spatial Structures, vol. 17, no. 3, pp. 43-46, 2011, in Chinese. 
[14] L.-C. Jiang, R. Gao, and G.-B. Xu, "Study on influence of different factors on support capacity of hollow spherical connectors," Journal of Northern Jiaotong University, vol. 22, no. 4, pp. 41-44, 1998, in Chinese.

[15] S.-S. Xiong, H. Ji, J. Deng, and Q.-C. Pan, "Finite element analysis and full-scale experimental research of complex loading on large-diameter welded hollow spherical joint," Engineering Mechanics, vol. 23, no. 1, pp. 184-188, 2006, in Chinese.

[16] H. Ji, S.-S. Xiong, and L.-T. Huang, "Finite element analysis and full-scale experimental study on large spherical joint in multi-axial loading," Engineering Mechanics, vol. 27, no. 4, pp. 173-178, 2010, in Chinese.

[17] H.-F. Liu, Y.-Z. Luo, and X. Xu, "Rigidity of welded hollow spherical joints on finite element analysis precession of reticulated shells," Engineering Mechanics, vol. 30, no. 1, pp. 350-358, 2013, in Chinese.

[18] Y.-K. Xiao, D.-Q. Qin, and Q.-R. Ma, "The stress analysis of crossed plate-sphere joints under tensile loadings," Journal of Taiyuan University of Technology, vol. 23, no. 2, pp. 45-52, 1992, in Chinese.

[19] Y.-K. Xiao, D.-Q. Qin, and Q.-R. Ma, "The fatigue strength of crossed plate-sphere joints," in Proceedings of the Sixth Proceedings of Space Structure, pp. 897-901, Guang Zhou, China, 1992, in Chinese.

[20] G.-B. Xu and J. Cui, "Fatigue of space trussed and its fatigue life calculation," Journal of Building Structures, vol. 15, no. 2, pp. 25-34, 1994, in Chinese.

[21] Y.-L. Zhang, J.-Y. Pan, and J.-L. Pan, "Analysis of common fatigue details in steel truss structures," Tsinghua Science and Technology, vol. 9, no. 5, pp. 583-588, 2004.

[22] J.-F. Jiao, The Theoretical and Experimental Research on Fatigue Performance of Crossed Plate Welded Hollow Spherical Connection in Plate-Type Grid Structure, Taiyuan University of Technology, Taiyuan, China, 2013, in Chinese.

[23] ANSI/AISC 360-16, Specification for Structural Steel Buildings, American Institute of Steel Construction, Chicago, IL, USA, 2010.

[24] J. C. McCormac and S. F. Csernak, Structures Steel Design, Pearson Higher Education, Upper Saddle River, NJ, USA, 5th edition, 2012.

[25] Eurocode3, Design of Steel Structures-Part 1.9: Fatigue, CEN: European Committee for Standardisation, Brussels, Belgium, 2003.

[26] GB 50017-2003, Code Design of Steel Structures, China Architecture and Building Press, Beijing, China, 2003, in Chinese.

[27] JGJ7-2010, Technical Specification for Space Frame Structures, China Architecture and Building Press, Beijing, China, 2010, in Chinese.

[28] Buildings Department, Code of Practice for the Structural Use of Steel, Buildings Department, Hong Kong, 2011.

[29] A. Fernández-Canteli, S. Blasón, J. A. F. O. Correia, and A. M. P. De Jesus, "A probabilistic interpretation of the Miner number for fatigue life prediction," Frattura ed Integrità Strutturale, vol. 30, pp. 327-339, 2014.

[30] S. Blasón, J. A. F. O. Correia, A. M. P. De Jesus, R. A. B. Calcada, and A. Fernández-Canteli, "A probabilistic analysis of Miner's law for different loading conditions," Structural Engineering and Mechanics, vol. 60, pp. 71-90, 2016.

[31] H.-B. Zhu, Z.-W. Yu, and L. Jiang, "Calculation method of equivalent fatigue stress range based on Corten-Dolan accumulative damage rule," Journal of Highway and
Transportation Research and Development, vol. 27, no. 1, pp. 54-57, 2010, in Chinese.

[32] JG/T 11-2009, Welded Hollow Spherical Node of Space Grid Structures, China Standard Press, Beijing, China, 2009, in Chinese.

[33] A. F. Hobbacher, Recommendations for Fatigue Design of Welded Joints and Components IIW Document IIW-2259-15, University of Applied Sciences, Munich, Germany, 2nd edition, 2016.

[34] A. Fatemi and L. Yang, "Cumulative fatigue damage and life prediction theories: a survey of the state of the art for homogeneous materials," International Journal of Fatigue, vol. 20 , no. 1, pp. 9-34, 1998.

[35] D.-G. Chen, "The method of determining the exponent $d$ in the Corten-Dolan's fatigue damage formular," Journal of Mechanical Strength, vol. 18, no. 1, pp. 21-24, 1996, in Chinese. 


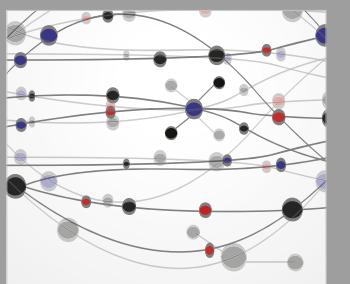

The Scientific World Journal
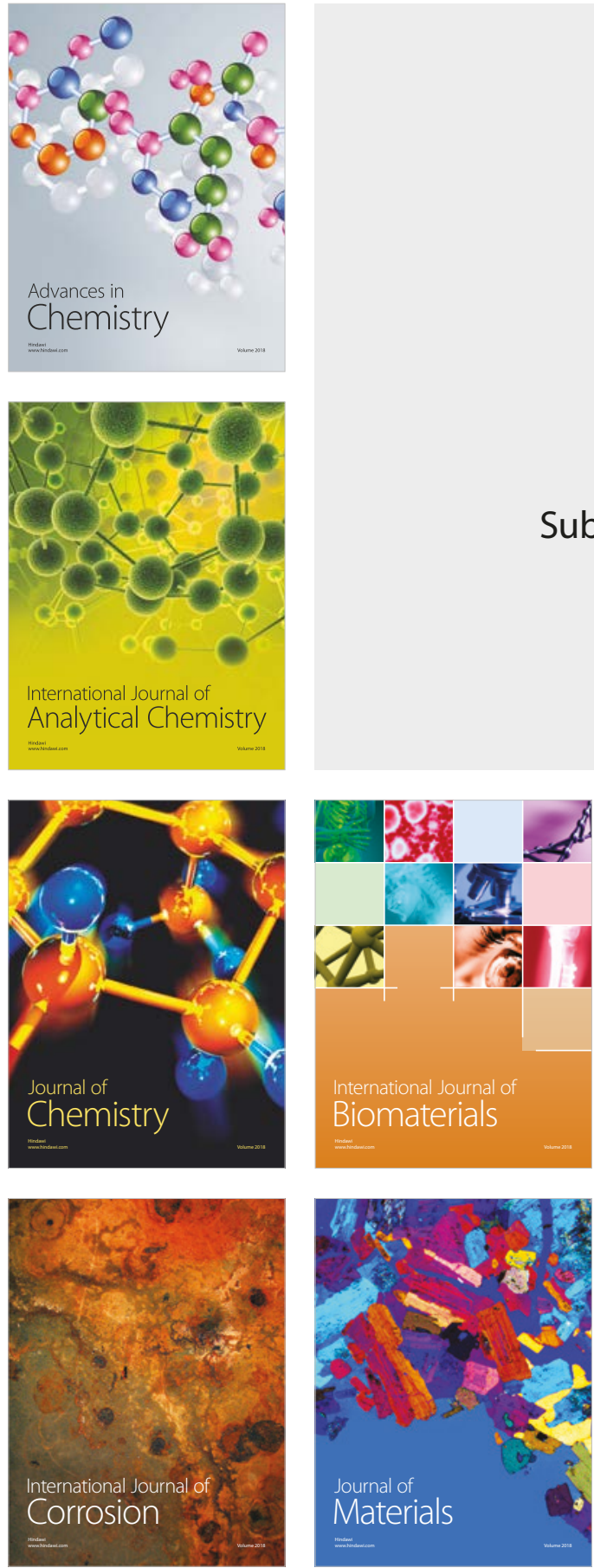

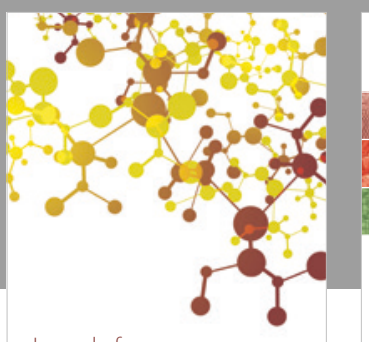

Journal of

Applied Chemistry
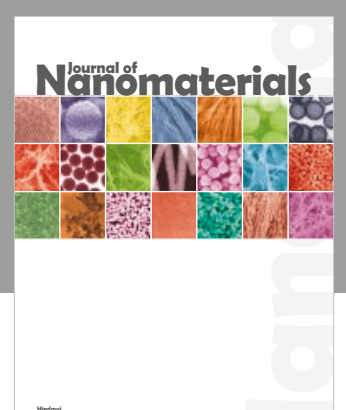

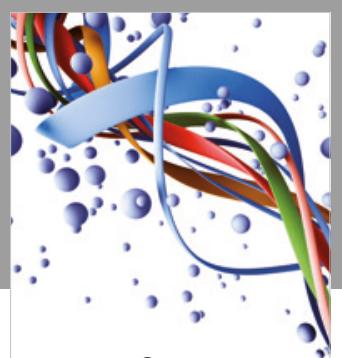

Scientifica

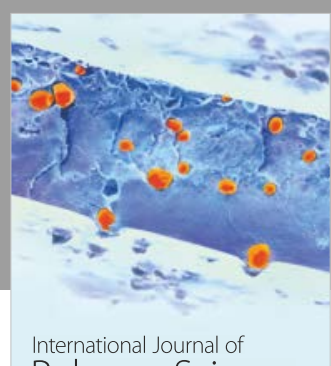

Polymer Science

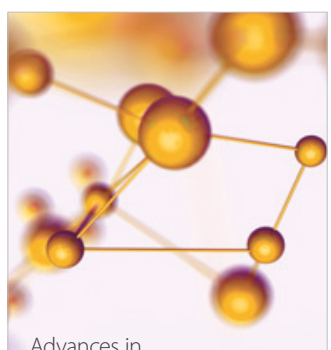

Physical Chemistry
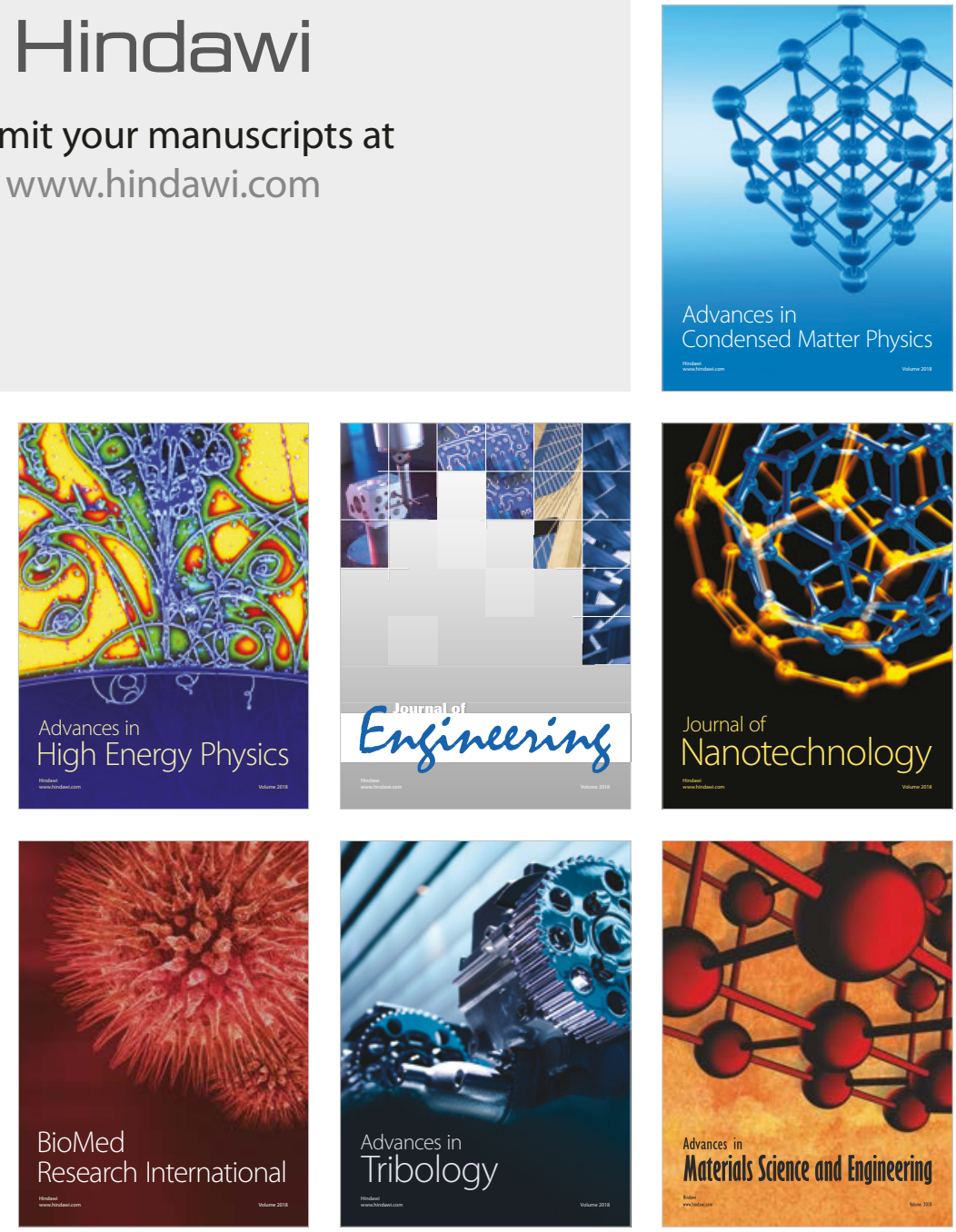